ISSN 1112-9867

\title{
EVALUATION OF RTD AND THERMOCOUPLE FOR PID TEMPERATURE CONTROL IN DISTRIBUTED CONTROL SYSTEM LABORATORY
}

\author{
D. A. A. Nazarudin, M. K. Nordin", A. Ahmad, M. Masrie, M. F. Saaid, N. M. Thamrin and
}

\author{
M. S. A. M. Ali
}

Faculty of Electrical Engineering, UniversitiTeknologi MARA, Shah Alam, Selangor, Malaysia

Published online: 10 November 2017

\begin{abstract}
Temperature process control is an integral element in the syllabus of control engineering. Generally, industrial processes can be simulated via proportional-integral-derivative(PID) controller and various tunings methods. This paper proposes a process control laboratory and sequence of experiments in basic temperature control process. The experiments are performed on temperature control plant using resistor temperature detector (RTD) and thermocouple in a distributed control system laboratory. Five PID experiments are conducted. These include optimum tuning of the controller using Ziegler-Nichols process reaction-curve method, ultimate gain and response of various proportional band, integral band and derivative band values to the temperature control. PID tuning is observed and analyzed for the respective RTD and thermocouple sensors.
\end{abstract}

Keywords: RTD; thermocouple; distributed control system; temperature process control.

Author Correspondence, e-mail: mkhai974@salam.uitm.edu.my

doi: http://dx.doi.org/10.4314/jfas.v9i6s.45 


\section{INTRODUCTION}

Experimental learning is an instructional approach that provides direct understanding on the knowledge being taught. The pedagogy involves self-action and self-determination, as well as hands-on activity. In essence, learning is a process where knowledge is being created through experience [1-2]. Reflective observations have known to benefit in the formation of new knowledge. By adopting experiential learning approach, students will be exposed to new experiences through projects that have connotations in the preceding courses. Hence, students are required to reflect on their existing knowledge to solve the given problems [3]. Innovative pedagogies have since been developed to improve the delivery approach[4-5]. Problem-based learning (PBL) is one method that has been designed to provide a focused, dynamic and problem-oriented approach in learning. The technique has been implemented in a wide range of academic specializations [6].

Generally, students are required to be physically involved in experiments and relate observations with the established theories. The reflections then allow crystallization of core knowledgewithin their mind [3]. Any discrepancies that occur during experiments or problems encountered will trigger the relevant brain segments to find a solution. Often, such tasks are best delegated in groups as there will usually be more than one answer for any encountered problem. The approach has proven to enhance students' understanding on the subject matter [4]. Consequently, these serves a bridge between the theories learned in formal education and critical thinking skills that are required in the industry [7-8]. PBL can be implemented in various formats such as mini-projects that are embedded in specific courses and open-ended experiments that mimic industry-related problems. Apart from practical knowledge and critical thinking skills, the pedagogy also improves the ability of students to work in teams.

Recently, academic activities in control engineering have been redesigned to match the requirements of manufacturing industries. Temperature control is one of the simpler forms of industrial process that can be simulated using PID controller in the laboratory [9-10]. The classical controller is still widely implemented to study characteristics and new tuning methods [11-12]. The temperature will depend on the adjustment of control variables, so that it conforms to the stability and other process requirements. To obtain a reliable output 
however, the controller must be well-tuned. A common approach to achieve optimum response is by using Ziegler-Nichols tuning method. The technique controls air temperature by adopting the tangent method in its open-loop test. Thus far, the Ziegler-Nichols approach has demonstrated the best rise time, settling time, and smallest integral absolute error [13]. Therefore, the study evaluates the temperature control [20] process of PID tuning module in the Distributed Control System (DCS) laboratory.

\section{OVEN TEMPERATURE SYSTEM}

Students are introduced to simple but real-time temperature control using PBL approach. Fig. 1 shows the temperature control [21] plant at the Faculty of Electrical Engineering, UniversitiTeknologi MARA. The plant is developed by Yokogawa for engineering education purposes and can be controlled using DCS technique. Temperature in the chamber is measured by RTD and thermocouple. Information from the sensors is used by the single-loop system to control the heater via continuous output current control [13].

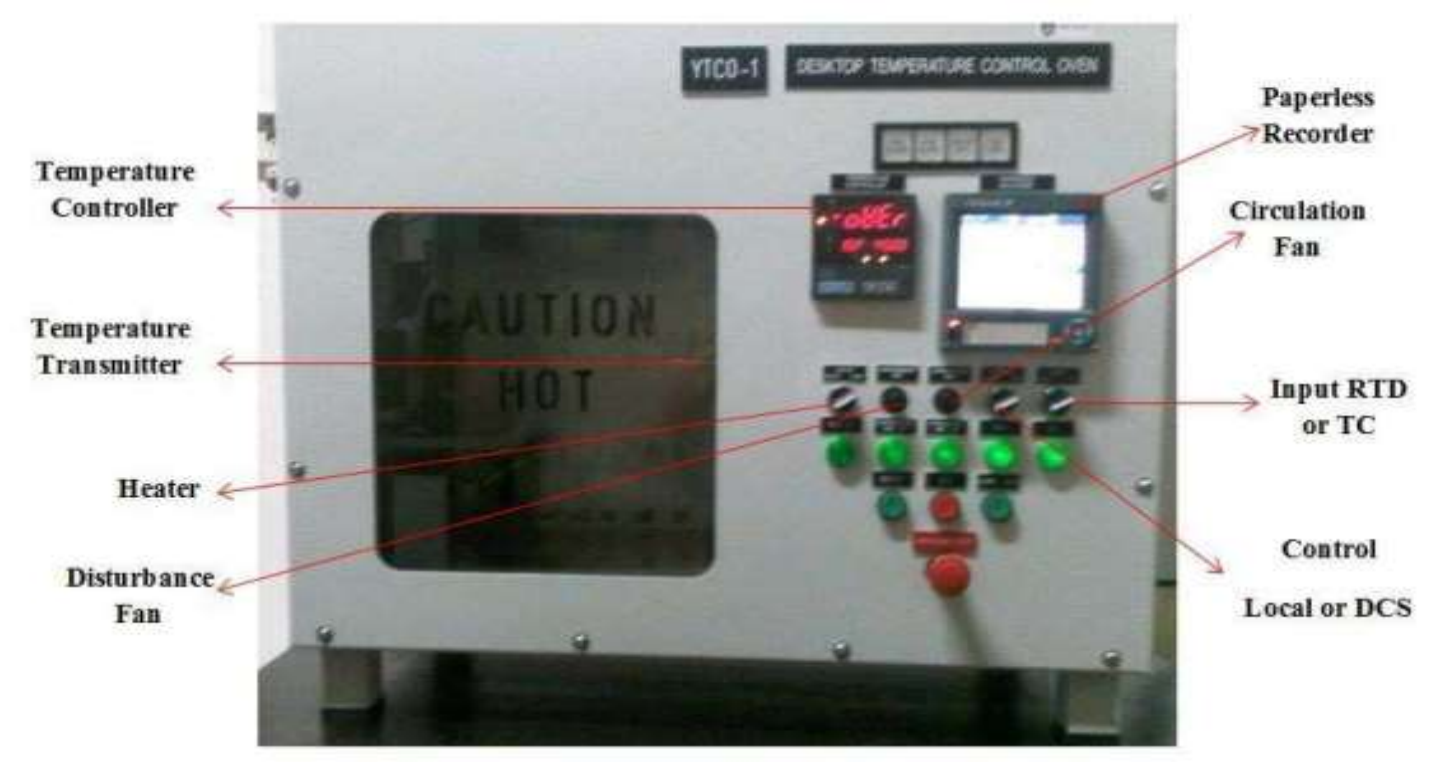

Fig.1. Temperature control plant [13]

\section{PID CONTROL}

Ziegler-Nichols method is used in the tuning process. Adjustments to the proportional, integral and derivative elements will influence the performance of PID controller [14]. Two 
widely used methods are closed-loop and open-loop tuning approaches. In the closed-loop method, the controller is tuned in the automatic state; operating in closed-loop configuration.Fig. 2 shows the typical ultimate gain curve tuning for closed-loop response [15].

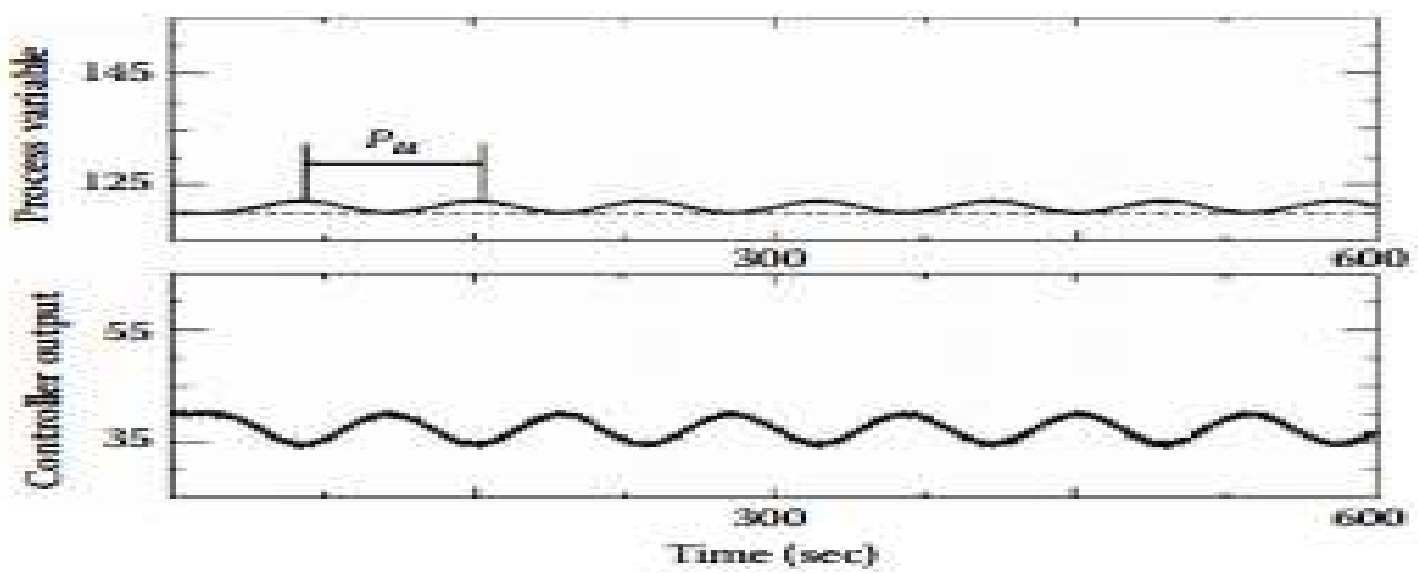

Fig.2.Ultimate gain curvetuning for closed-loop response [16]

Meanwhile, the open-loop technique is a method that tunes the controller in manual state; the plant is operating in open-loop configuration. Fig. 3 shows the typical process reaction curve open-loop response [15].

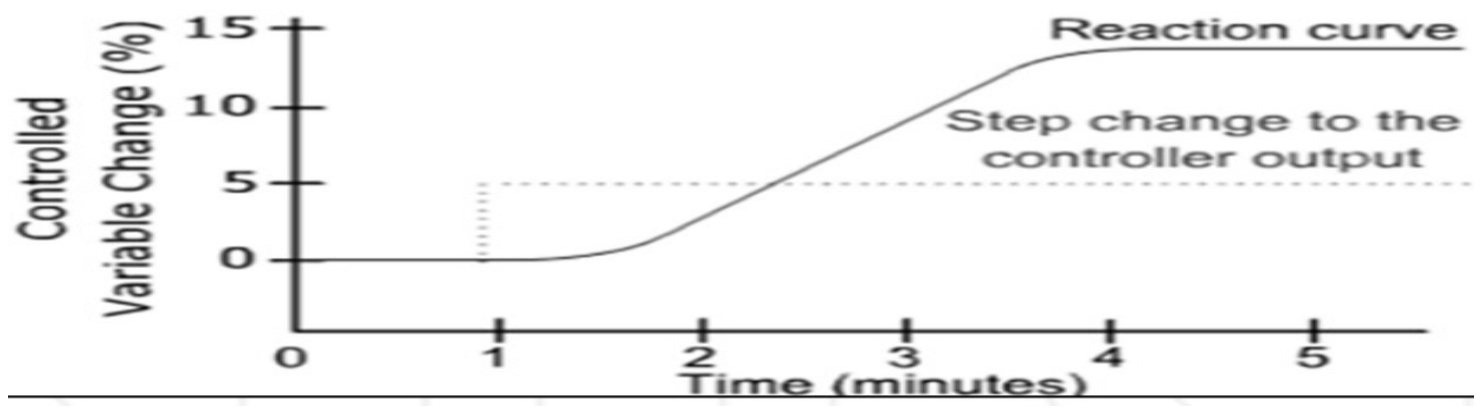

Fig.3.Process reaction curve foropen-loop response [17]

\section{METHODOLOGY}

\subsection{RTD and Thermocouple}

RTD and thermocouple are commonly used sensors to measure temperature for monitoring and control purposes. In this study, the two sensors used by the Yokogawa plant is thermocouple type J and PT100 RTD sensors. 


\subsection{PID}

Table 1 and Table 2 each show the optimization of process reaction curve and ultimate gain curve. Both optimization processes are performed using Ziegler-Nichols tuning method. RR, $T_{d}, T_{I}, T_{D}, P U$ and PBU, each denotes reaction rate, dead time, integral time, derivative time, period of ultimate gain and proportional band ultimate gain.

Table 1.Optimization of process reaction curve using Ziegler-Nichols method [18]

\begin{tabular}{cccc}
\hline $\begin{array}{c}\text { Controller } \\
\text { Mode }\end{array}$ & Proportional Band & Integral Time, & Derivative Time, \\
\hline P & $100 \times \mathrm{RR}^{\circ} \times \mathrm{T}_{\mathrm{d}}$ & $\mathbf{T}_{\mathbf{I}}(\mathbf{s})$ & $\mathbf{T}_{\mathbf{D}}(\mathbf{s})$ \\
PI & $111.1 \times \mathrm{RR} \times \mathrm{T}_{\mathrm{d}}$ & $3.33 \times \mathrm{T}_{\mathrm{d}}$ & Off \\
PID & $83.3 \times \mathrm{RR} \times \mathrm{T}_{\mathrm{d}}$ & $2.0 \times \mathrm{T}_{\mathrm{d}}$ & $0.5 \times \mathrm{OU}$ \\
\hline
\end{tabular}

Table 2.Optimization of ultimate gain curve using Ziegler-Nichols method [18]

\begin{tabular}{cccc}
\hline $\begin{array}{c}\text { Controller } \\
\text { Mode }\end{array}$ & $\begin{array}{c}\text { Proportional Band } \\
(\mathbf{\%})\end{array}$ & $\begin{array}{c}\text { Integral Time, } \\
\text { Derivative Time, }\end{array}$ & $\begin{array}{c}\mathbf{T}_{\mathbf{D}}(\mathbf{s}) \\
\text { P }\end{array}$ \\
PI & $2 \times \mathrm{PBU}$ & Off & Off \\
PID & $2.2 \times \mathrm{PBU}$ & $0.83 \times \mathrm{PU}$ & Off \\
\hline
\end{tabular}

\section{EXPERIMENTS AND TUNING}

\subsection{Open Reaction Curve Determination with Continuous Output Current Control}

Initially, a simple open-loop test is performed to determine the value of $T_{d}$, time constant $\left(T_{c}\right)$ and gain $\left(\mathrm{K}_{\mathrm{p}}\right)$ using tangent method. The desired temperature is set to $45^{\circ} \mathrm{C}$ and the response is analyzed. Then, the values for proportional band, integral time and derivative time are calculated using Ziegler-Nichols tuning method shown in Table 1. The experiment is conducted with set point change function of DCS from manual to automatic mode. In closed-loop configuration, the performance is evaluated in terms of dynamic response.

\subsection{Ultimate Gain Method Using Continuous Current Control Output}

In the next experiment, the desired temperature is also set to $45^{\circ} \mathrm{C}$. The PID values are each set to $\mathrm{P}=10, \mathrm{I}=1$ and $\mathrm{D}=0$. The set point value is then changed to $55^{\circ} \mathrm{C}$ and the response is 
analyzed to determine PU and PBU. The values of proportional band, $T_{I}$ and $T_{D}$ are each calculated using the equations shown in Table 2.

\subsection{Effect of Different Proportional Band Values}

Similar temperature setting of $45^{\circ} \mathrm{C}$ is used for the subsequent experiment. The controller is already in automatic mode but with different values of proportional bands in the PID settings. The response is observed to determine settling time $\left(T_{s}\right)$, rise time $\left(T_{r}\right)$, percentage overshoot $(\% \mathrm{OS})$, steady-state error $(\% \mathrm{SSE})$, oscillation and decay ratio. The experiment is repeated for different proportional band values and changes in response are compared.

\subsection{Effect of Different Integral and Derivative Time Values}

The study adopts a similar method as the preceding experiment. Observations however, focus on comparing the effect of changes in integral and derivative values on the response.

\section{RESULTS AND DISCUSSION}

\subsection{Open Reaction Curve: Tangent Method}

Fig. 4 and Fig. 5 each show the resultant process reaction curve for the open-loop test. A step change of manipulated variable (MV) changed from $30 \%$ to $45 \%$. Initially, the steady state temperature is $36.1^{\circ} \mathrm{C}$. Then, it requires between 20 to 30 minutes to reach a new steady state for both RTD and thermocouple sensors. Using the tangent method, values of Tc, RR and Td are then calculated using tangent method. Fig. 4 shows the output reaction curve for RTD sensor. 


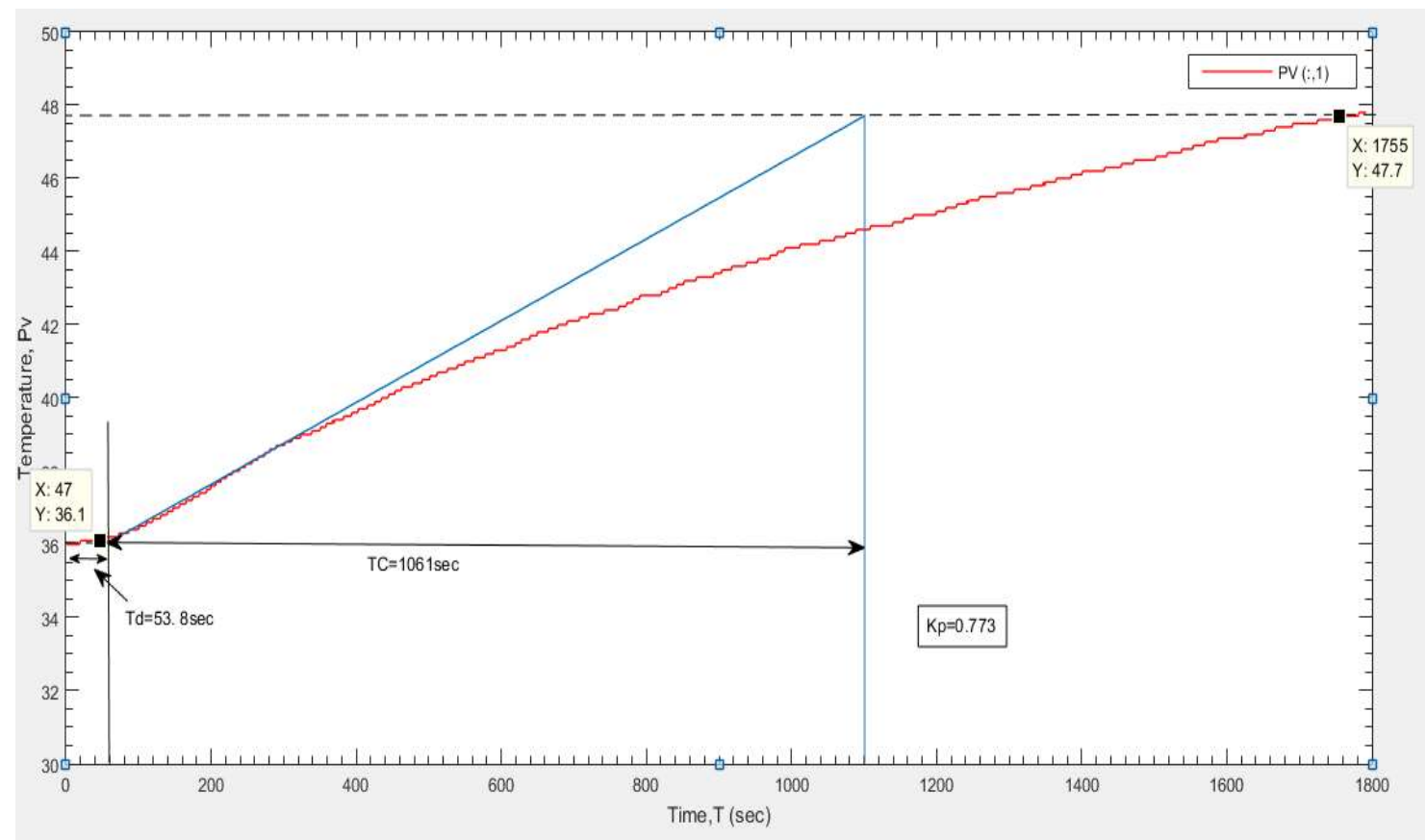

Fig.4. Process reaction curve with RTD input

The RR for RTD is determined by the following computation.

$$
\begin{gathered}
\mathrm{T}_{\mathrm{c}}=138.0 \mathrm{~mm} \times \frac{200 \mathrm{~s}}{26.0 \mathrm{~mm}}=1061 \mathrm{~s} \\
\mathrm{RR}=\frac{\Delta P V / \mathrm{T}_{\mathrm{c}}}{\Delta \mathrm{MV}}=\frac{11.6 / 1061}{15}=0.0007 \mathrm{~s}^{-1} \\
\mathrm{~T}_{\mathrm{d}}=7.0 \mathrm{~mm} \times \frac{200 \mathrm{~s}}{26.0 \mathrm{~mm}}=53.8 \mathrm{~s}
\end{gathered}
$$

Meanwhile, the output reaction curve for thermocouple sensor is shown in Fig. 5. 


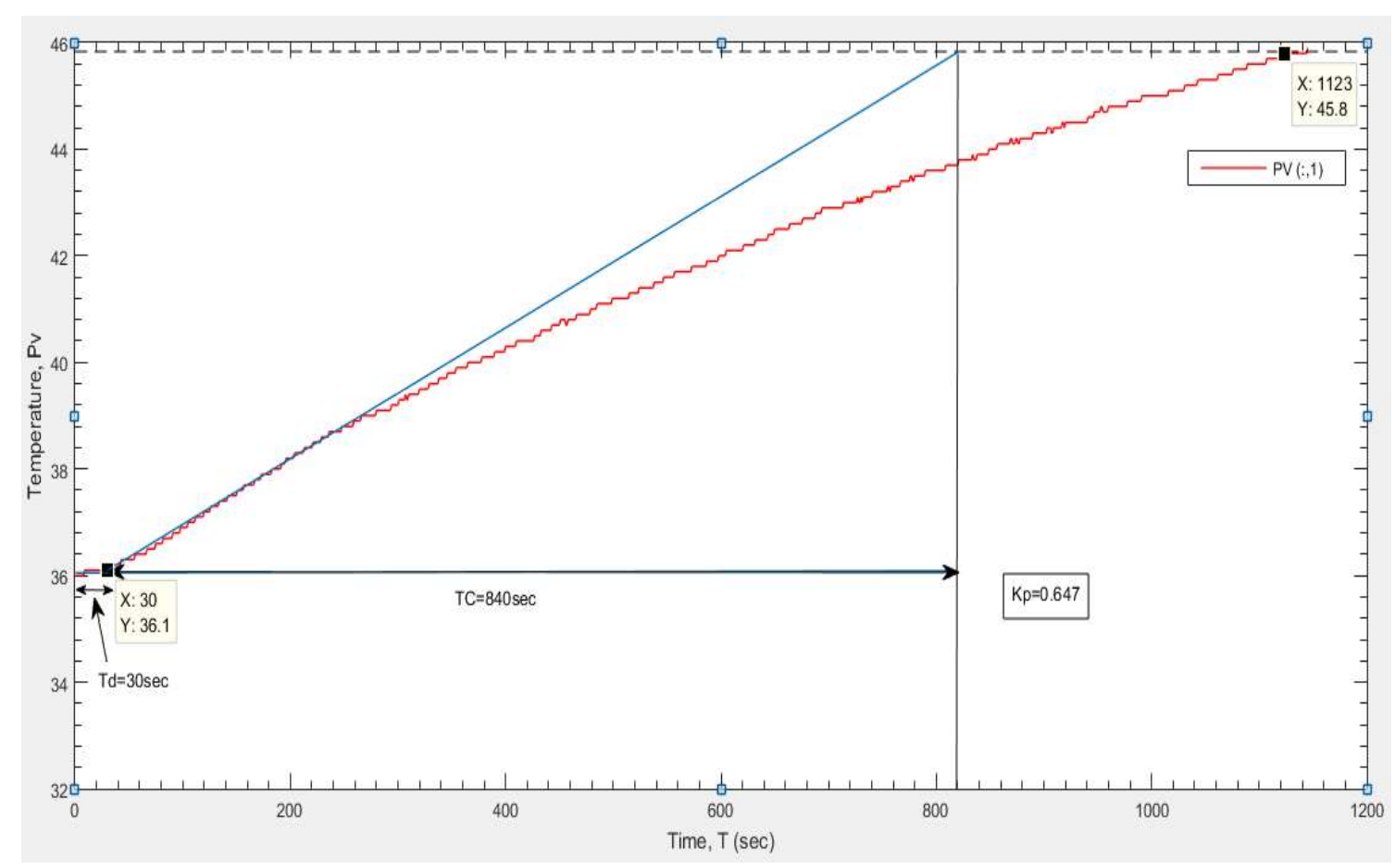

Fig.5. Process reaction curve with thermocouple input

The RR for thermocouple sensor is determined by the following computation.

$$
\begin{gathered}
\mathrm{T}_{\mathrm{c}}=168.0 \mathrm{~mm} \times \frac{200 \mathrm{~s}}{40.0 \mathrm{~mm}}=840 \mathrm{~s} \\
\mathrm{RR}=\frac{\Delta P V / \mathrm{T}_{\mathrm{c}}}{\Delta \mathrm{MV}}=\frac{9.7 / 840}{15}=0.0007 \mathrm{~s}^{-1} \\
\mathrm{~T}_{\mathrm{d}}=6.0 \mathrm{~mm} \times \frac{200 \mathrm{~s}}{40.0 \mathrm{~mm}}=30.0 \mathrm{~s}
\end{gathered}
$$

\subsection{Ultimate Gain Curve Determination: Process Identification Method}

Ultimate gain curve tuning is a trial-and error method that is still widely adopted [18]. Parameters for PBU and PU are determined from the output of the oscillation response shown in Fig. 6 and Fig. 7. 


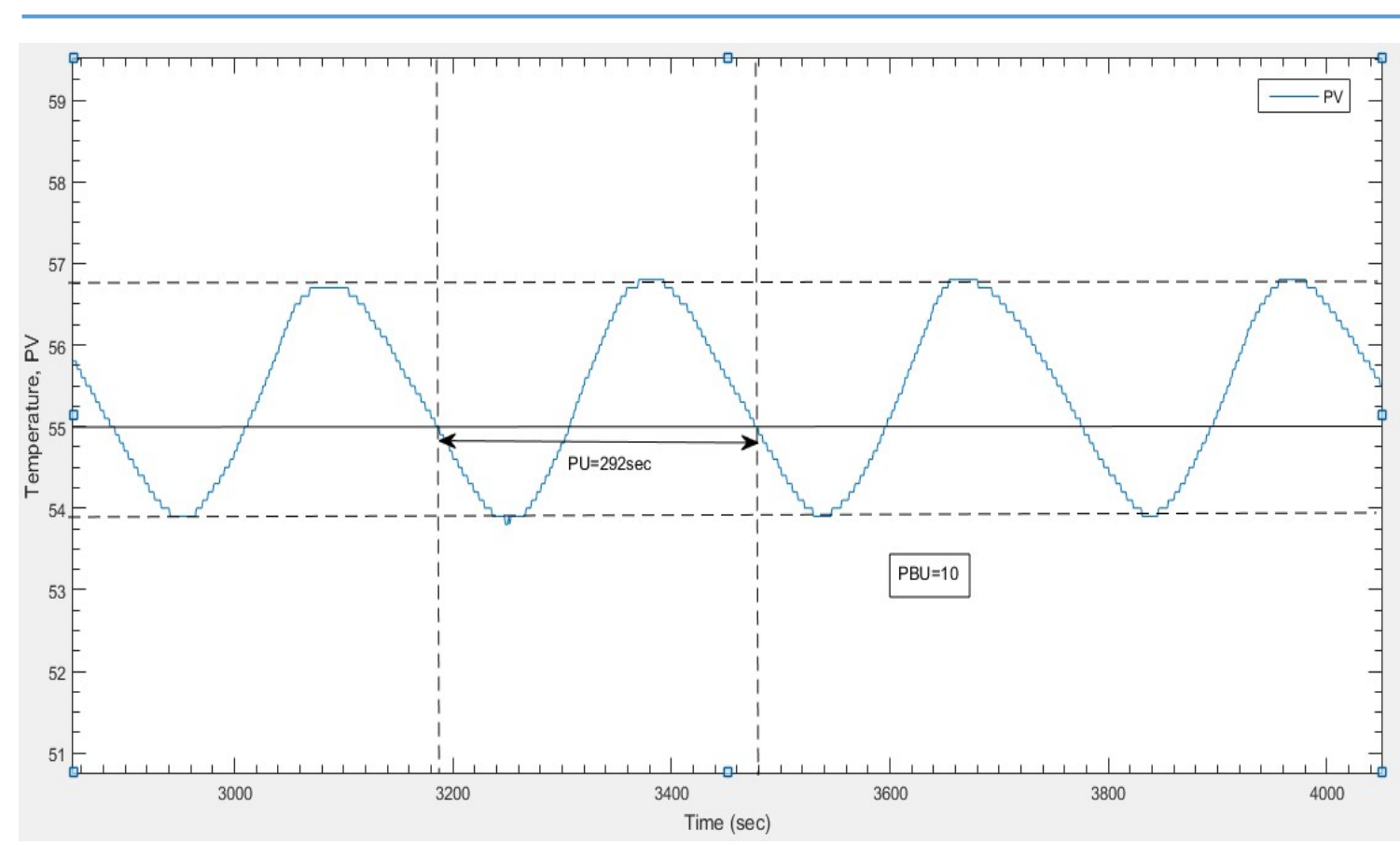

Fig.6. Ultimate gain curve with RTD input

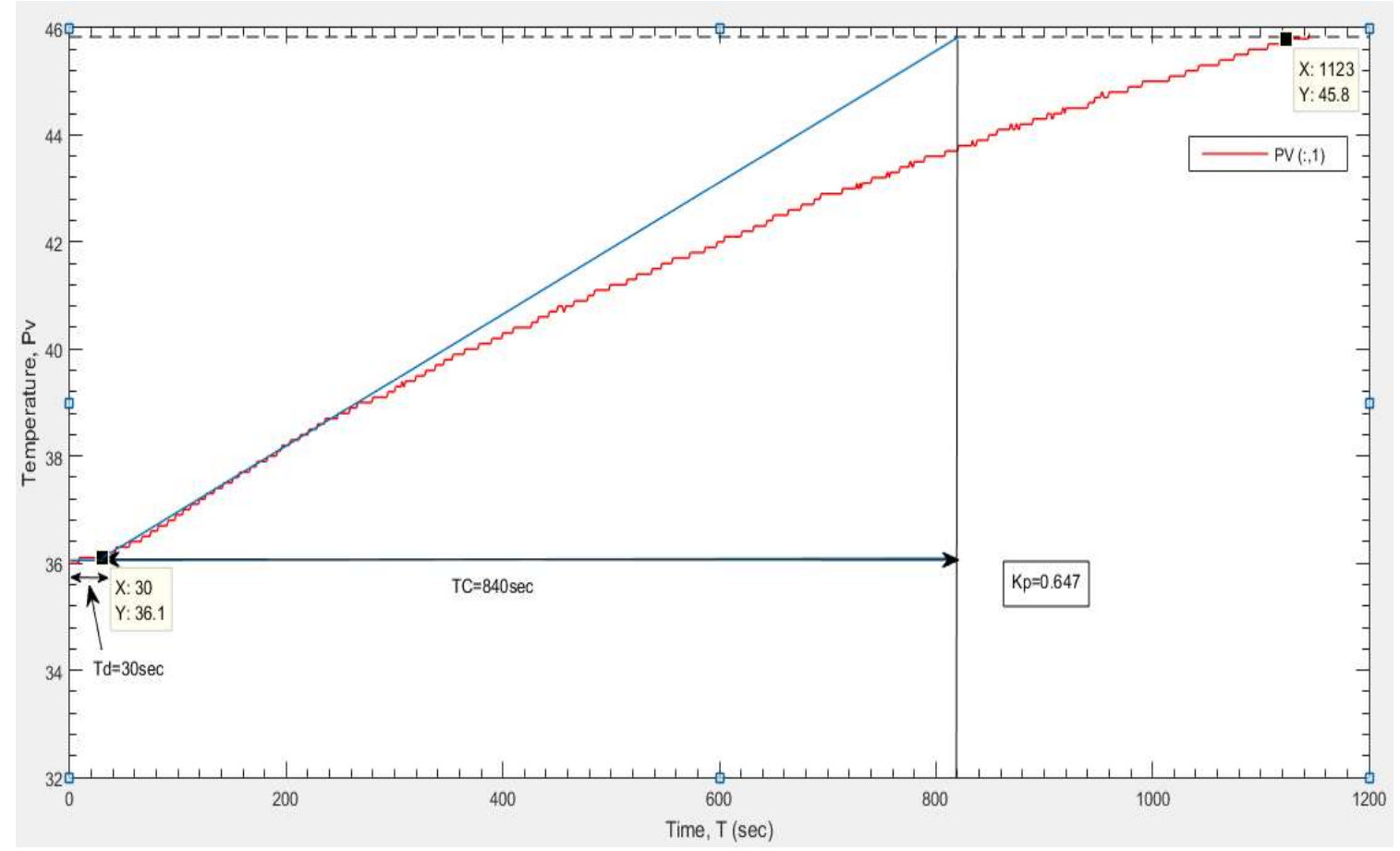

Fig.7. Ultimate gain curve with thermocouple input

\subsection{PID Tuning}

Values of the proportional band, $\mathrm{T}_{\mathrm{I}}$ and $\mathrm{T}_{\mathrm{D}}$ are determined by parameters calculated in section 6.1. Table 4 and Table 5 each summarizes the optimized values for the reaction curves for RTD and thermocouple sensors based on Ziegler-Nichols tuning method. 
Table 4.Optimization of process reaction curve with RTD input

\begin{tabular}{cccc}
\hline $\begin{array}{c}\text { Controller } \\
\text { Mode }\end{array}$ & $\begin{array}{c}\text { Proportional Band } \\
\mathbf{( \% )}\end{array}$ & $\begin{array}{c}\text { Integral Time, } \\
\mathbf{T}_{\mathbf{I}}(\mathbf{s})\end{array}$ & $\begin{array}{c}\text { Derivative Time, } \\
\mathbf{T}_{\mathbf{D}}(\mathbf{s})\end{array}$ \\
\hline P & 3.766 & Off & Off \\
PI & 4.184 & 170.154 & Off \\
PID & 3.137 & 107.6 & 26.9 \\
\hline
\end{tabular}

Table 5.Optimization of process reaction curve with thermocouple input

\begin{tabular}{cccc}
$\begin{array}{c}\text { Controller } \\
\text { Mode }\end{array}$ & $\begin{array}{c}\text { Proportional Band } \\
\mathbf{( \% )}\end{array}$ & $\begin{array}{c}\text { Integral Time, } \\
\mathbf{T}_{\mathbf{I}}(\mathbf{s})\end{array}$ & $\begin{array}{c}\text { Derivative Time, } \\
\mathbf{T}_{\mathbf{D}}(\mathbf{s})\end{array}$ \\
\hline P & 2.1 & Off & Off \\
PI & 2.333 & 99.9 & Off \\
PID & 1.7489 & 60 & 15 \\
\hline
\end{tabular}

Meanwhile, Fig. 8 and Fig. 9 each show the output characteristics in terms of dynamic responses which include peak time $\left(\mathrm{T}_{\mathrm{p}}\right), \% \mathrm{OS}, \% \mathrm{SSE}, \mathrm{T}_{\mathrm{r}}$ and $\mathrm{T}_{\mathrm{s}}$.

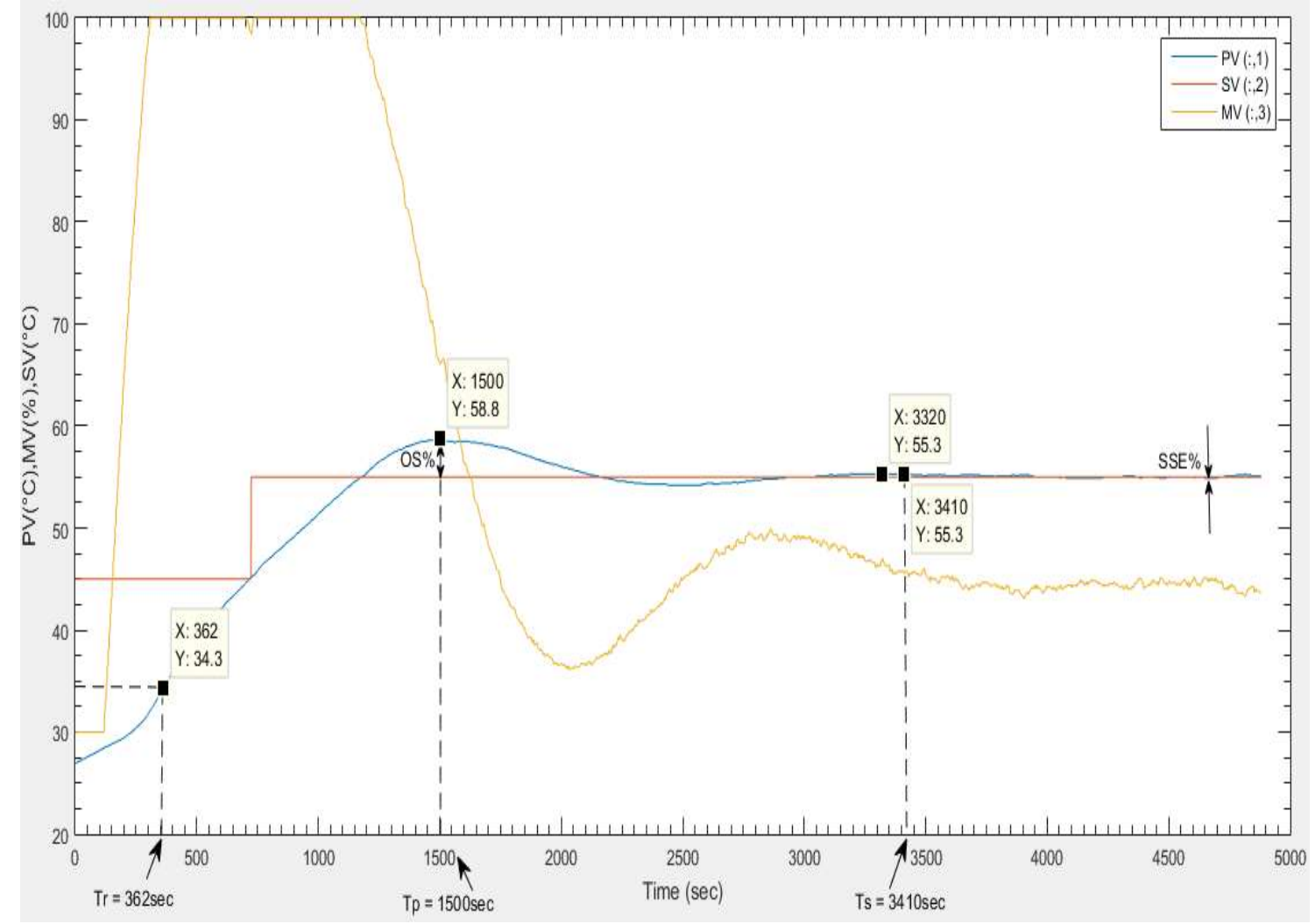

Fig.8. Closed-loop response of PID tuning with RTD input 


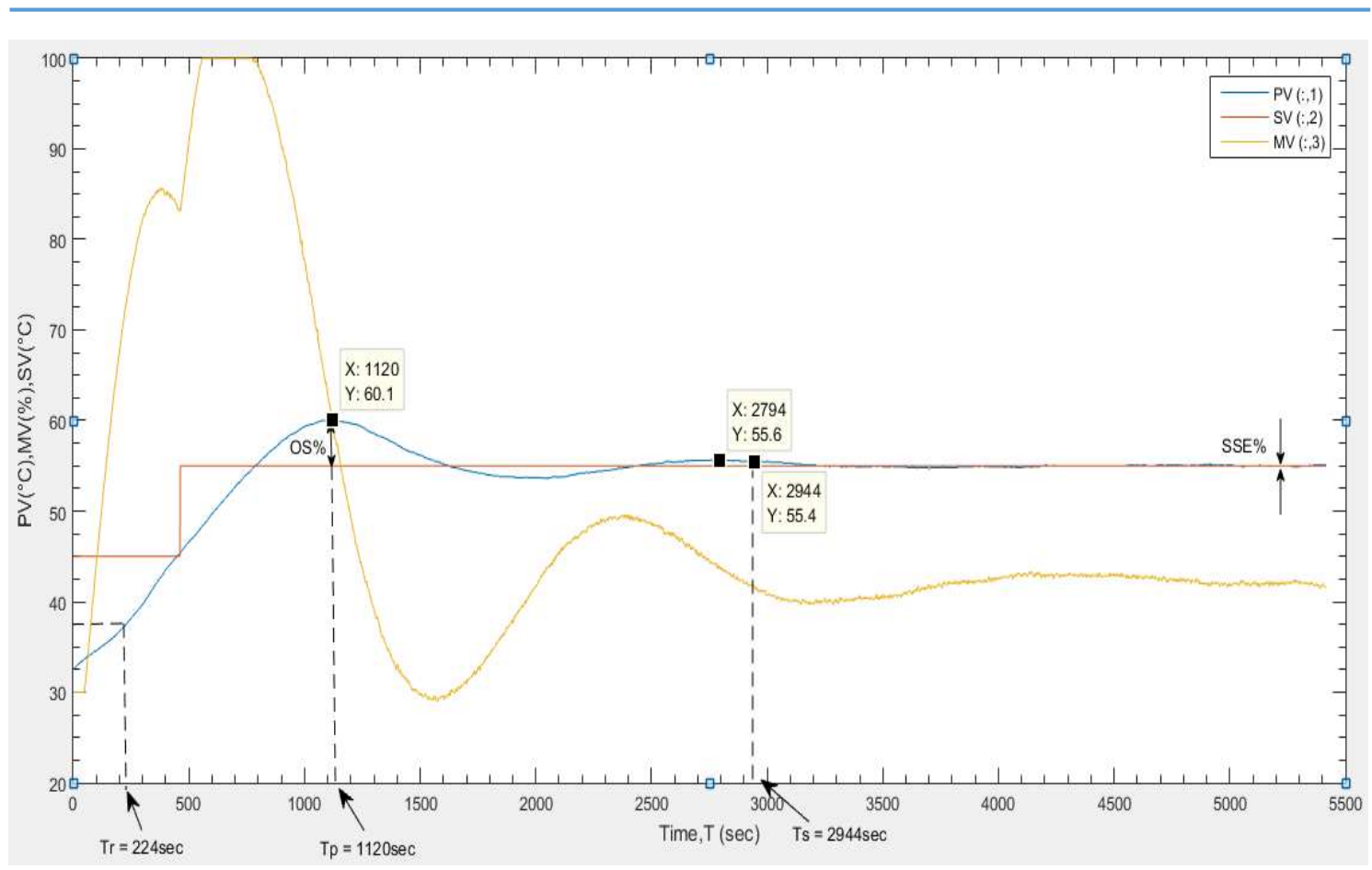

Fig.9. Closed-loop response of PID tuning with thermocouple input

The values of PBU and PU are determined via process identification method. The parameters are then used to calculate the proportional band, TI and TD. Subsequently, the optimized ultimate gain curve for RTD and thermocouple inputs are each shown in Table 6 and Table 7. The parameters are tuned using Ziegler-Nichols method.

Table 6.Optimization of ultimate gain curve with RTD input

\begin{tabular}{cccc}
\hline $\begin{array}{c}\text { Controller } \\
\text { Mode }\end{array}$ & $\begin{array}{c}\text { Proportional Band } \\
(\mathbf{\%})\end{array}$ & $\begin{array}{c}\text { Integral Time, } \\
\mathbf{T}_{\mathbf{I}}(\mathbf{s})\end{array}$ & $\begin{array}{c}\text { Derivative Time, } \\
\mathbf{T}_{\mathbf{D}} \mathbf{( s )}\end{array}$ \\
\hline P & 20 & Off & Off \\
PI & 22 & 534.36 & Off \\
PID & 17 & 146 & 36.5 \\
\hline Table 7.Optimization of ultimate gain curve with thermocouple input \\
\hline Controller & Proportional Band & Integral Time, & Derivative Time, \\
Mode & $\mathbf{( \% )}$ & $\mathbf{T}_{\mathbf{I}}(\mathbf{s})$ & $\mathbf{T}_{\mathbf{D}}(\mathbf{s})$ \\
\hline P & 30 & Off & Off \\
PI & 33 & 267.26 & Off \\
PID & 25.5 & 161 & 40.25 \\
\hline
\end{tabular}


Meanwhile, the dynamic responses for all the process for RTD and thermocouple sensors are shown in Fig. 10 and Fig. 11 respectively.

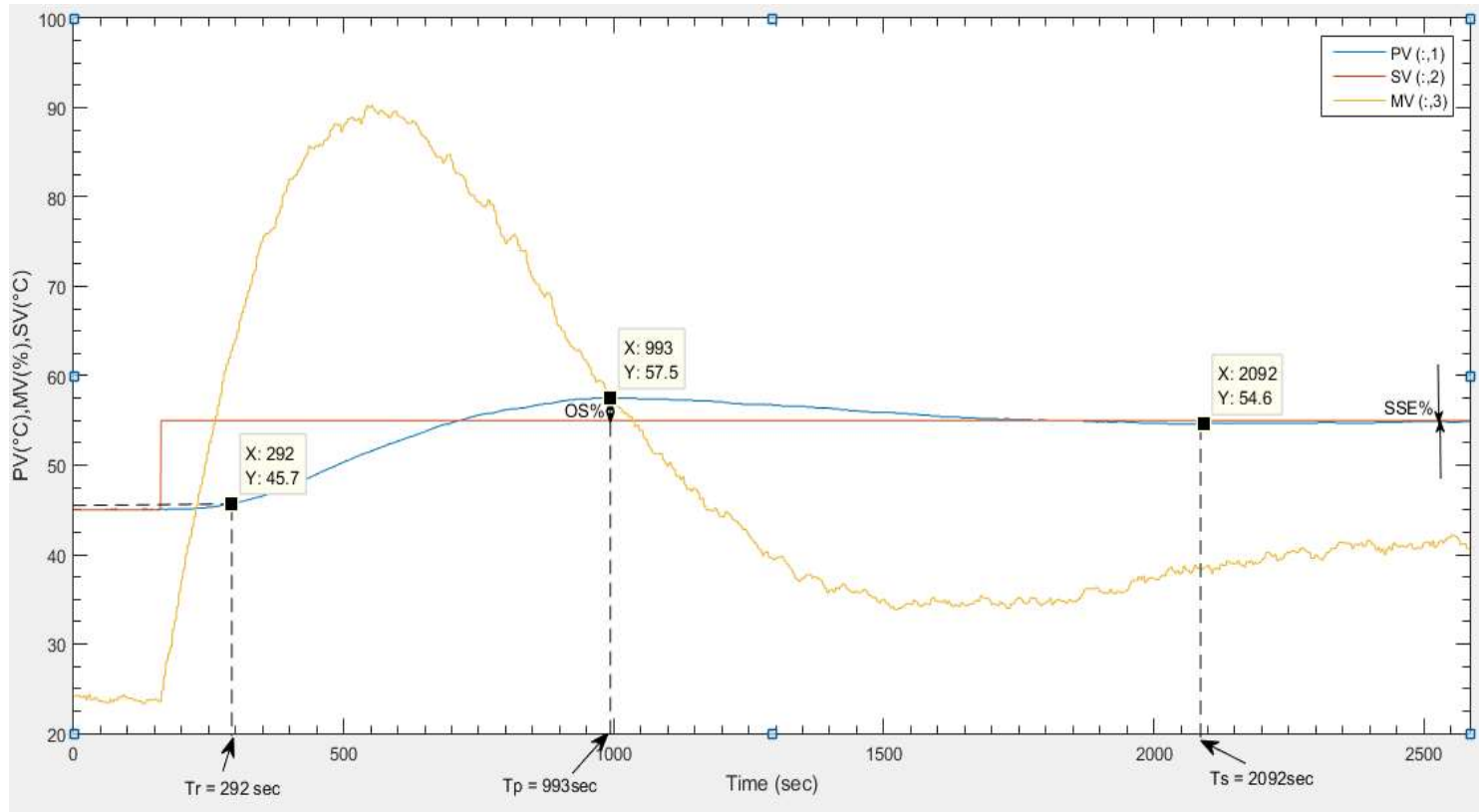

Fig.10. Output response of PID tuning with RTD input

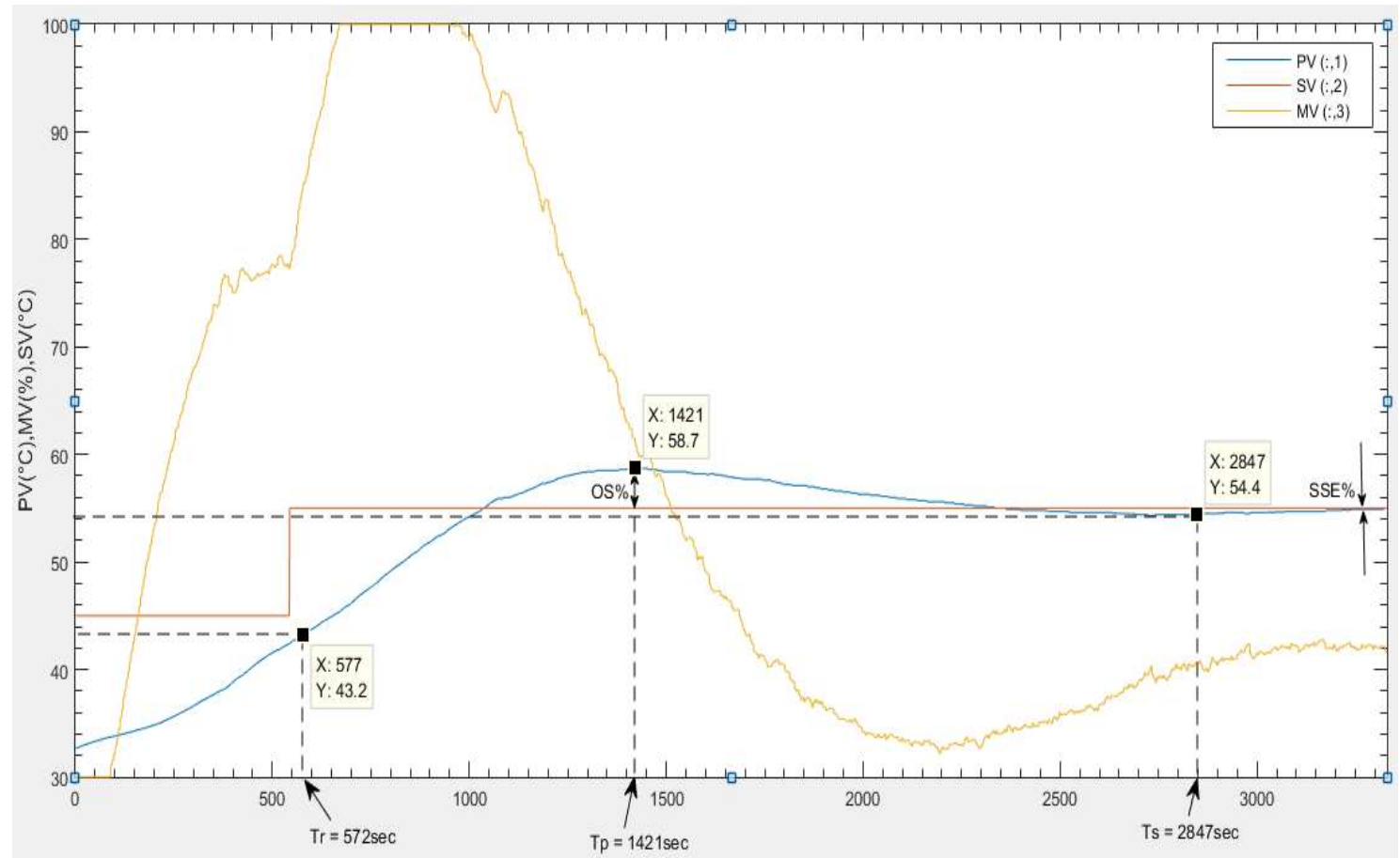

Fig.11. Output response of PID tuning with thermocouple input

Fig. 12, Fig. 13 and Fig. 14 each shows the effect of changing the values of proportional band, $T_{I}$ and $T_{D}$ on the temperature being measured with RTD sensor. Differences have been observed in terms of its dynamic response. 


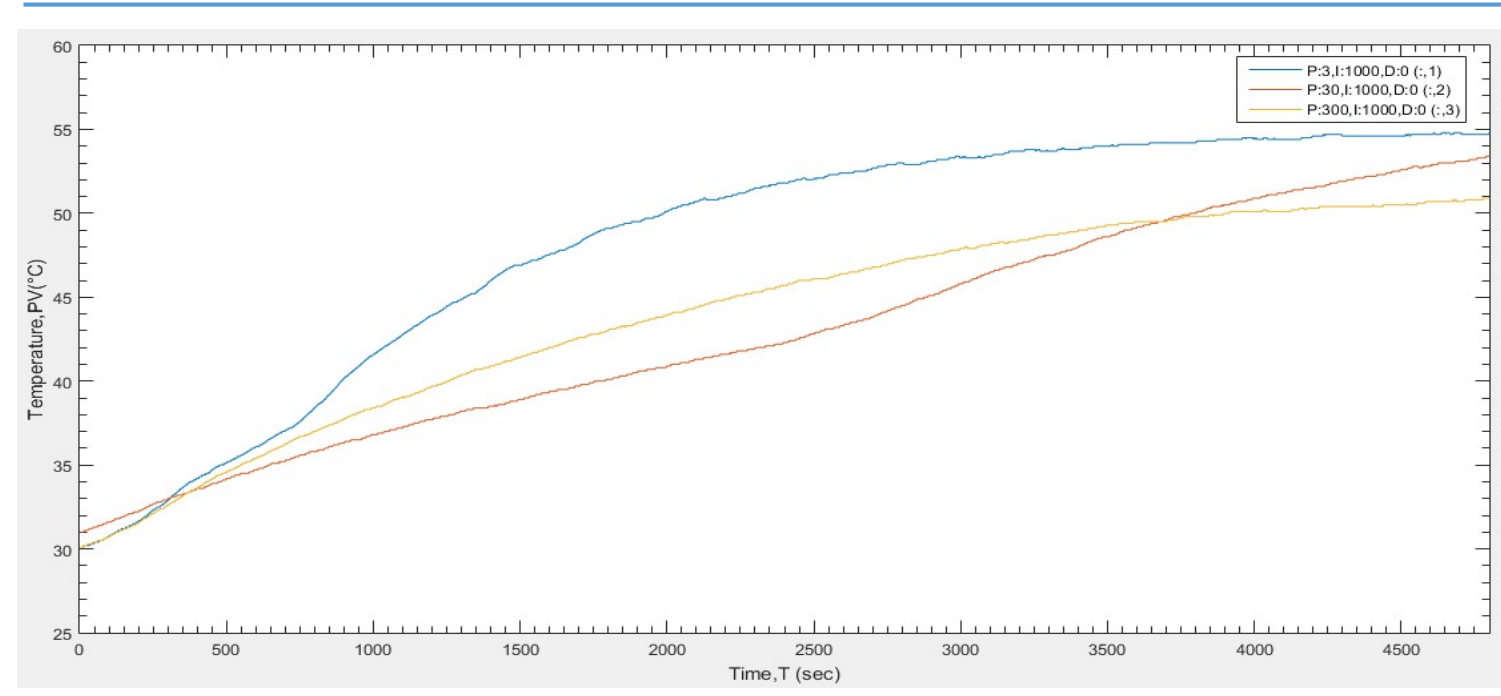

Fig.12. Effect on temperature measured using RTD with change of proportional band

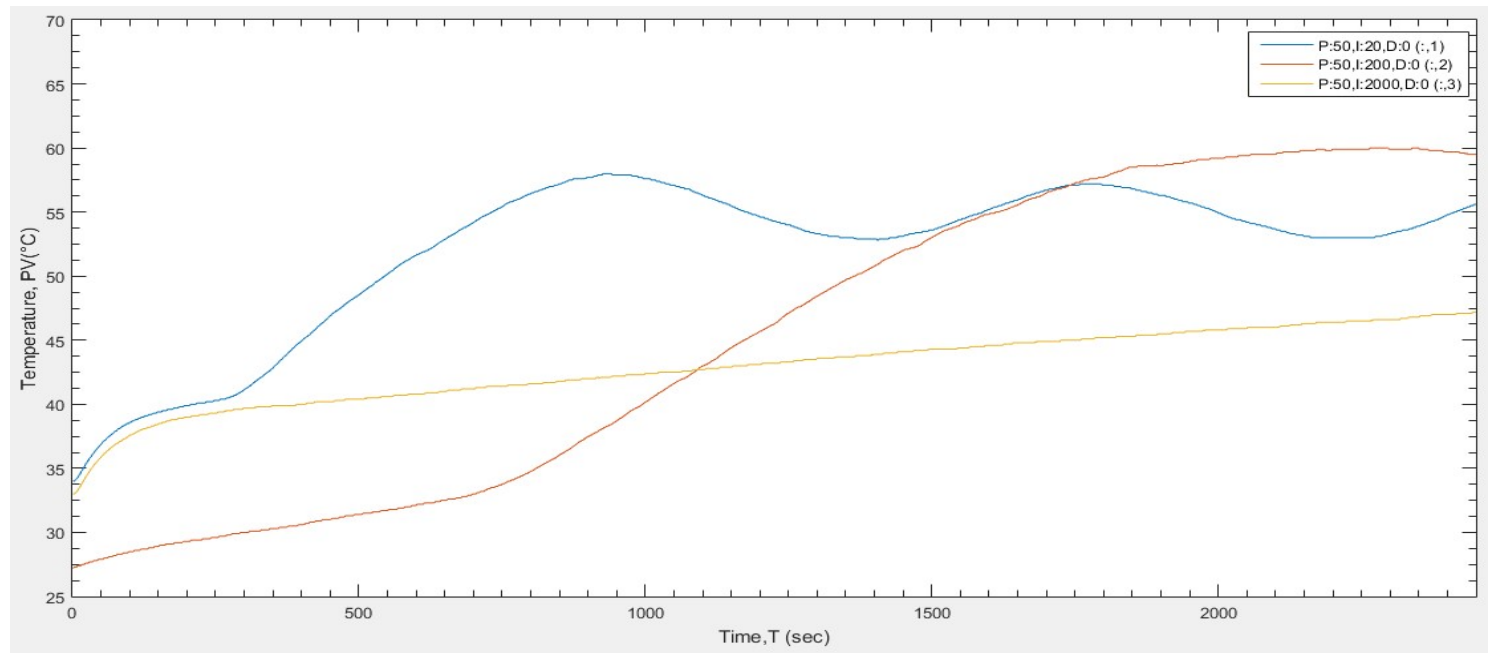

Fig.13. Effect on temperature measured using RTD with change of $T_{I}$

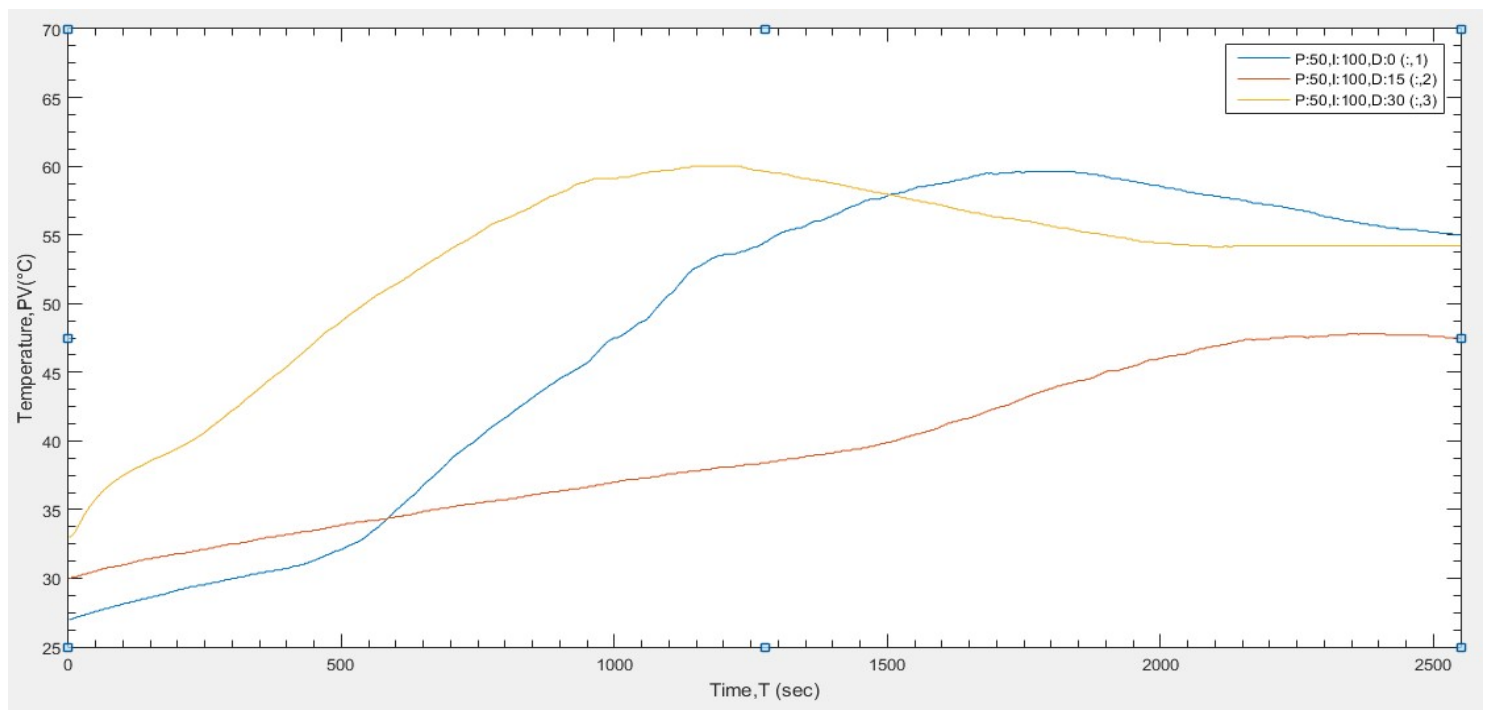

Fig.14. Effect on temperature measured using RTD withchange of $T_{D}$ 
Meanwhile, Table 8 summarizes the changes of tuning values that affect temperature measurement through RTD.

Table 8. Effect of tuning values to temperature measurement using RTD

\begin{tabular}{cccc}
\hline \multicolumn{2}{c}{ Input } & RTD Sensor & Remarks \\
\hline P & 3 & Refer to Fig. 12 & I $=0$ (fixed) \\
& 30 & & $\mathrm{D}=0$ (fixed) \\
& 300 & & P and D in Offset Mode \\
I & 20 & Refer to Fig. 13 & $\mathrm{P}=50$ (fixed) \\
& 200 & & $\mathrm{D}=0$ (fixed) \\
& 2000 & & $\mathrm{D}$ in Offset Mode \\
$\mathrm{D}$ & 0 & Refer to Fig. 14 & $\mathrm{P}=50$ (fixed) \\
& 15 & & $\mathrm{I}=100$ (fixed) \\
& 30 & &
\end{tabular}

Similarly, Fig. 15, Fig. 16 and Fig. 17 each shows the effect of changing the values of proportional band, $T_{I}$ and $T_{D}$ on the temperature being measured using thermocouple sensor. Differences have also been observed in terms of its dynamic response.

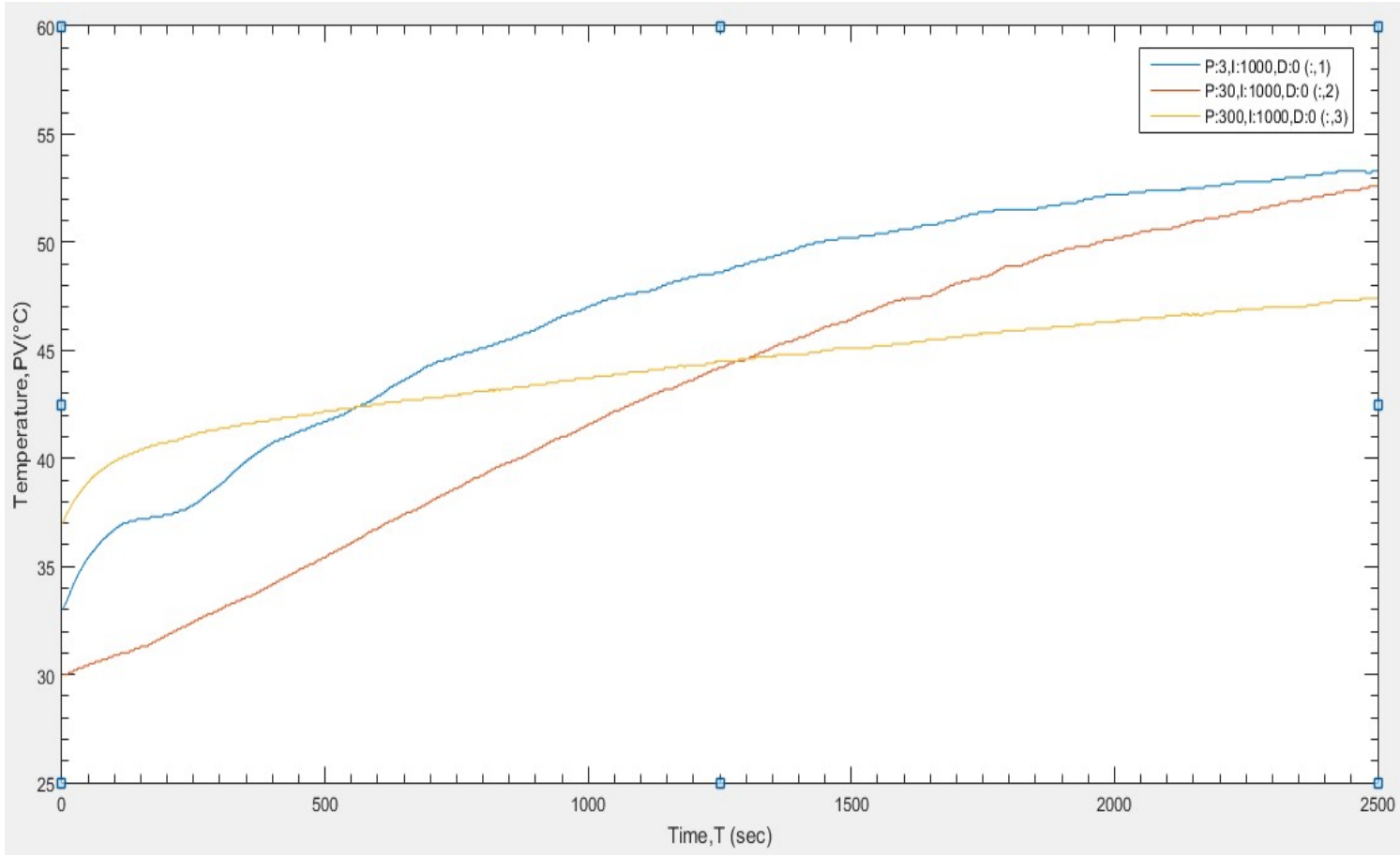

Fig.15.Effect on temperature measured using thermocouple with change of proportional band 


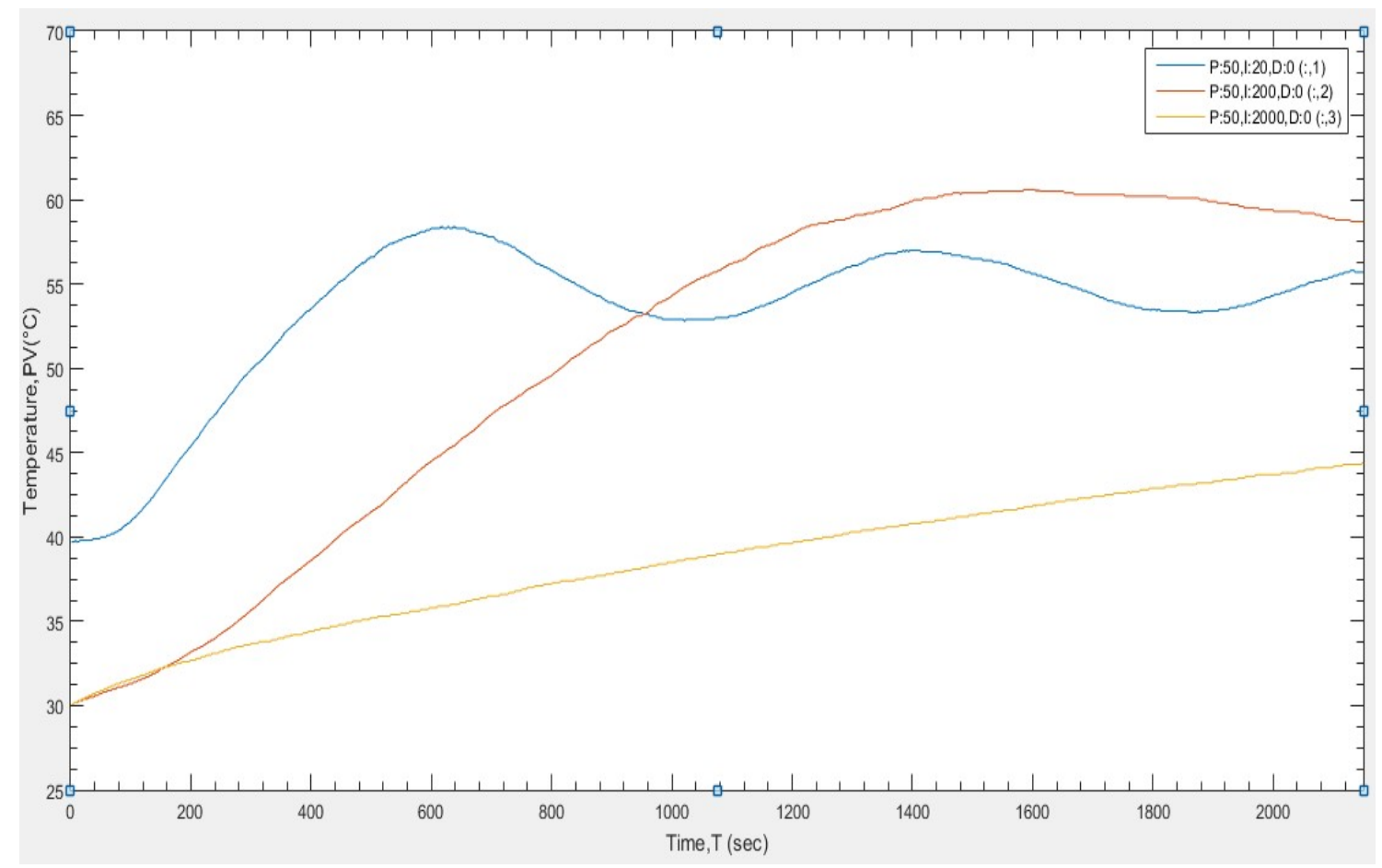

Fig.16.Effect on temperature measured using thermocouple with change of $T_{I}$

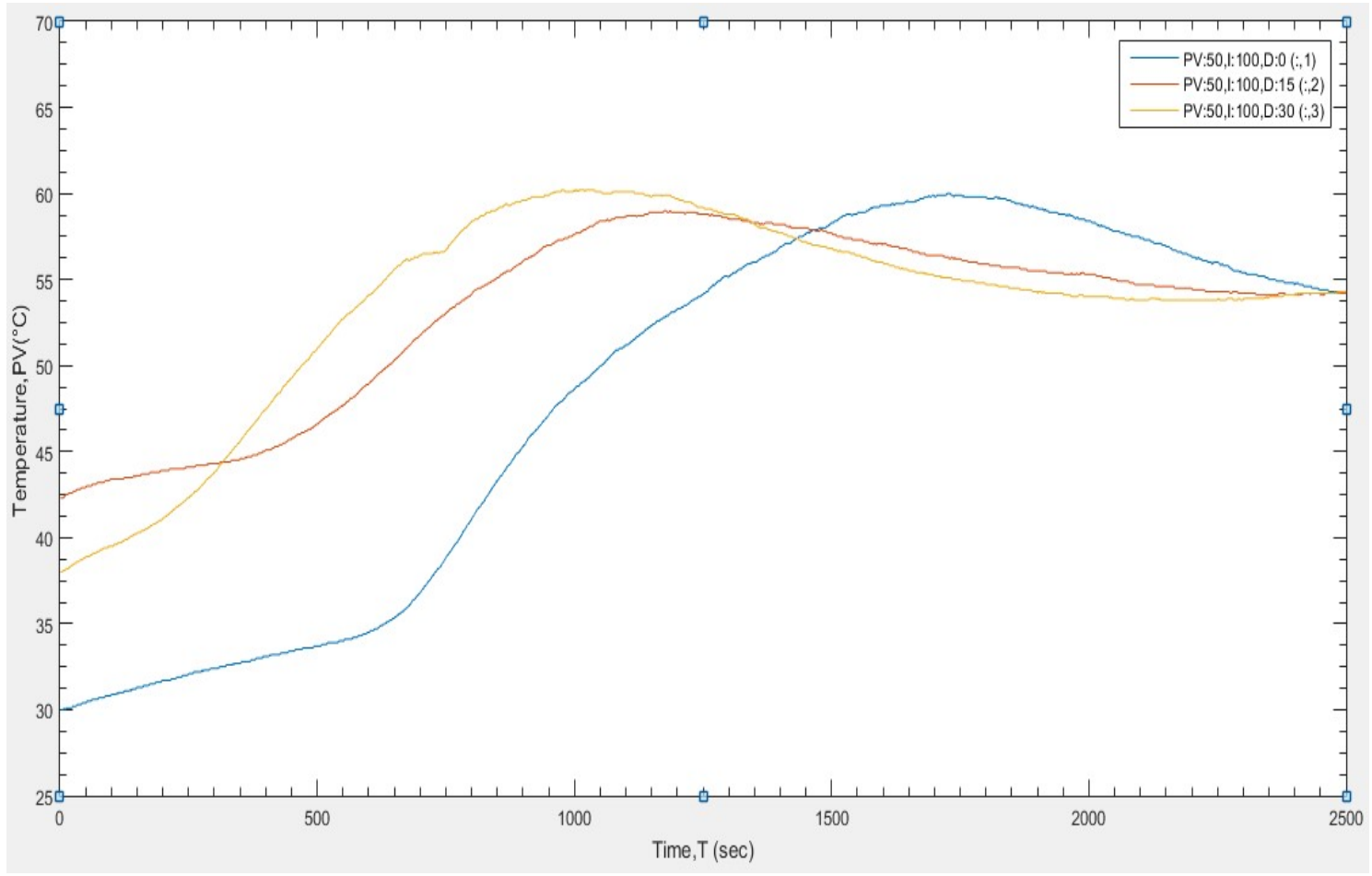

Fig.17.Effect on temperature measured using thermocouple with change of $T_{D}$

In addition, Table 9 shows the changes of tuning values that affect temperature measurement through use of thermocouple sensor. 
Table 9. Effect of tuning values to temperature measurement using thermocouple sensor

\begin{tabular}{cccc}
\hline \multicolumn{2}{c}{ Input } & RTD Sensor & Remarks \\
\hline P & 3 & Refer to Fig. 15 & $\mathrm{I}=0$ (fixed) \\
& 30 & & $\mathrm{D}=0$ (fixed) \\
& 300 & & P and D in Offset Mode \\
$\mathrm{I}$ & 20 & Refer to Fig. 16 & $\mathrm{P}=50$ (fixed) \\
& 200 & & $\mathrm{D}=0$ (fixed) \\
& 2000 & & $\mathrm{D}$ in Offset Mode \\
$\mathrm{D}$ & 0 & Refer to Fig. 17 & $\mathrm{P}=50$ (fixed) \\
& 15 & & $\mathrm{I}=100$ (fixed) \\
& 30 & &
\end{tabular}

\section{CONCLUSION}

The studyhas successfully evaluatedRTD and thermocouple sensors for PID [19] temperature control [22] in DCS laboratory using Ziegler-Nichols tuning method. Future work will include investigation on other time integral performance criteria such as integral square error, integral absolute error and integral time-weighted absolute error. The task that can be executed in MATLAB Simulink will specifically investigate and improve the error of the process response. Further study can also be done for on and off states, as well as time proportional aspects of process control.

\section{ACKNOWLEDGEMENTS}

This study is funded by the Institute of Research Management and Innovation, UniversitiTeknologi MARA(600-IRMI/DANA 5/3/ARAS (0076/2016)).

\section{REFERENCES}

[1] Miettinen R. The concept of experiential learning and John Dewey's theory of reflective thought and action. International Journal of Lifelong Education, 2000, 19(1):54-72

[2] Chan C K Y. Exploring an experiential learning project through Kolb's Learning Theory using a qualitative research method. European Journal of Engineering Education, 2012, 
37(4):405-415

[3] Hiebert J, Morris A K, Glass B. Learning to learn to teach: An 'experiment' model for teaching and teacher preparation in mathematics. Journal of Mathematics Teacher Education, 2003, 6(3):201-222

[4] Moh M, Alvarez-Horine R. A successful graduate cloud computing class with hands-on labs. In IEEE Frontiers in Education Conference, 2013, pp. 1156-1162

[5] Mekali H V, Patil P. Project based learning for a course on advanced microcontroller: Experiment and results: A case study for BMS College of Engineering, Bangalore, India. In IEEE International Conference on MOOC, Innovation and Technology in Education, 2014, pp. 128-131

[6] Greenberg J E, Delgutte B, Gray M L. Hands-on learning in biomedical signal processing. IEEE Engineering in Medicine and Biology Magazine, 2003, 22(4):71-79

[7] Rodríguez D, Sicilia M A, Cuadrado-Gallego J J, Pfahl D. E-learning in project management using simulation models: A case study based on the replication of an experiment. IEEE Transactions on Education, 2006, 49(4):451-463

[8] RatanK, Perry M. Hands-on approach to senior design class in engineering technology. In IEEE Frontiers in Education Conference, 1997, pp. 542-545

[9] William K. Temperature-control strategies for industrial processes. IEEE Transactions onIndustry and General Applications, 1969, 5(6):735-739

[10] Gao Z, Trautzsch T A, and Dawson J G. A stable self-tuning fuzzy logic control system for industrial temperature regulation. IEEE Transactions on Industrial Applications, 2002, $38(2): 414-424$

[11] Zhang R, Xue A, Gao F. Temperature control of industrial coke furnace using novel state space model predictive control. IEEE Transactions on Industrial Informatics, 2014, 10(4):2084-2092

[12] Xiaohong P, Zhi M,Laisheng X. Research and application on GA-based two-stage fuzzy temperature control system for a type of industrial furnace. In International Conference on Electrical and Control Engineering, 2010, pp. 1558-1561

[13] Hambali N, Ang A A R, Ishak A A,Janin Z. Various PID controller tuning for air temperature oven system. In IEEE International Conference on Smart Instrumentation, 
Measurement and Applications, 2013, pp. 1-5

[14] Hambali N, Janin Z, Samsudin N S M,Ishak A A. Process controllability for air temperature oven system using open-loop reformulated tangent method. In IEEE International Conference on Smart Instrumentation, Measurement and Applications, 2013, pp. 1-6

[15] Shahrokhi M, Zomorrodi A. Comparison of PID controller tuning methods. 2013, http://www.ie.tec.ac.cr/einteriano/control/clase/Zomorrodi_Shahrokhi_PID_Tunning_Compar ison.pdf

[16] Murrill P. W. Automatic control of processes. Scranton: International Textbook Co., 1967

[17] Seborg D. E., Mellichamp D. A., Efgar T. F., Doyle F. J. Process dynamics and control,New Jersey: John Wiley and Sons, 2011

[18] IshakA. A., Abdullah Z. PID tuning: Fundamental concepts and applications. Selangor:UniversitiTeknologi MARA Press, 2013

[19] Nawi B, Sulaini B, Mohd Z A R, Shamsul A Z,Zairi I R. PID voltage control for DC motor using MATLAB Simulink and Arduino microcontroller. Journal of Applied Environmental and Biological Sciences, 2015, 5(9):166-173

[20] Rizman Z I, Yeap K H, Ismail N, Mohamad N, Husin N H. Design an automatic temperature control system for smart electric fan using PIC. International Journal of Science and Research, 2013, 2(9):1-4

[21] Abdullah R, Rizman Z I, Dzulkefli N N, Ismail S, Shafie R, Jusoh M H.Design an automatic temperature control system for smart tudungsaji using Arduino microcontroller. ARPN Journal of Engineering and Applied Sciences, 2016, 11(16):9578-9581

[22] Dzulkefli N N, Abdullah R, Jaafar A N, Shafie R, Yassin I M, Rizman Z I, Abidin H Z. Design an automatic temperature control system based on PIC controller for smart ventilation fan. Journal of Fundamental and Applied Sciences, 2017, 9(3S):779-790

\section{How to cite this article:}

D. A. A. Nazarudin, M. K. Nordin, A. Ahmad, M. Masrie, M. F. Saaid, N. M. Thamrin and M. S. A. Megat Ali. Evaluation of RTD and thermocouple for PID temperature control in distributed control system laboratory. J. Fundam. Appl. Sci., 2017, 9(6S), 600-617. 